\title{
ASPECTOS DA ORGANIZAÇÃO E FUNCIONAMENTO DO ATENDIMENTO EDUCACIONAL ESPECIALIZADO: UM ESTUDO EM LARGA ESCALA
}

\author{
Mara Silvia Pasian" \\ Universidade Federal de São Carlos (UFSCar), São Carlos - SP, Brasil \\ Enicéia Gonçalves Mendes** \\ Universidade Federal de São Carlos (UFSCar), São Carlos - SP, Brasil \\ Fabiana Cia"** \\ Universidade Federal de São Carlos (UFSCar), São Carlos - SP, Brasil
}

RESUMO: Há uma série de legislações que regulamentam a política de inclusão escolar e o acesso dos alunos Público-alvo da Educação Especial (PAEE) à classe comum da rede de ensino público brasileiro. Além do acesso dos alunos PAEE às classes comuns, é fundamental garantir a sua permanência e seu sucesso na escolarização e sua integração. Objetivou-se, com este estudo, conhecer a opinião dos professores de Salas de Recursos Multifuncionais (SRM) sobre a organização do Atendimento Educacional Especializado (AEE). Foi aplicado um questionário on-line em larga escala, que coletou repostas de 1.202 professores de SRM das redes municipais de ensino de 20 estados e mais de 150 municípios. Os resultados apontam a) dificuldades no atendimento em horário contrário à sala de aula comum, b) número de SRM insuficiente em algumas regiões e c) necessidade de apoio de outros profissionais.

Palavras-chave: Educação especial. Inclusão escolar. Atendimento Educacional Especializado.

ASPECTS OF THE ORGANIZATION AND FUNCTIONING OF SPECIALIZED EDUCATIONAL SERVICE: A LARGE-SCALE STUDY

ABSTRACT: There is a number of regulations establishing a policy of educational inclusion and the access of 'target audience' student of special

http://dx.doi.org/10.1590/0102-4698155866

Elocation-id - e155866

"Pós-doutorado pela Universidade Federal de São Carlos (UFSCar) na área de Educação Especial com apoio da Fundação de Amparo à Pesquisa do Estado de São Paulo (FAPESP). Doutora em Psicologia pela Universidade de São Paulo (USP). Integrante do Observatório Nacional de Educação Especial (ONEESP). E-mail: <marasilvia123@yahoo.com.br>.

“Doutora em Psicologia pela Universidade de São Paulo (USP). Professora Titular da Universidade Federal de São Carlos (UFSCar), Departamento de Psicologia, do Programa de Pós-Graduação em Educação Especial. Coordenadora da rede de pesquisadores do Observatório Nacional de Educação Especial (ONEESP). E-mail: < eniceia.mendes@gmail.com>.

"“*Doutora em Educação Especial pela Universidade Federal de São Carlos. Professora da Universidade Federal de São Carlos (UFSCar), Departamento de Psicologia, do Programa de Pós-Graduação em Educação Especial. Vice-coordenadora da rede de pesquisadores do Observatório Nacional de Educação Especial (ONEESP). E-mail: < fabianacia@hotmail.com > 
Brazilian education services to the common classroom of Brazilian public network teaching. In addition to the access of special students to the common classroom, it is important to ensure that this policy and therefore the educational service offered to the children needing special care are indeed effective the desired successful schooling. The main objective of this investigation was to assess the impressions of school teachers working in concerning the organization and operation of the specialized educational services. For this purpose, a large scale survey was carried out, collecting data from 1.202 teachers of multifunctional resource classes of the municipal school systems, with answers from 150 cities of 20 States of Brazil. Results point a) difficulties in attendance at times contrary to the common classroom, b) number of multifunctional resource classes is insufficient, and c) the assistance of another professionals is required.

Keywords: Special education. School inclusion. Specialized Educational Services.

\section{LES ASPECTS DE L'ORGANISATION ET LE FONCTIONNEMENT DE SERVICES D'ÉDUCATION SPÉCIALISÉE: UNE ÉTUDE À GRANDE ÉCHELLE}

RÉSUMÉ: Diverses lois régissant la politique de l'insertion scolaire pour public cible de l'accès des élèves de l'enseignement spécial dans une classe ordinaire brésilien. Est important de vérifier la qualité de l'enseignement pour assurer le succès dans ces études. Objectif de cette étude était de connaitre la réalité sur l'organisation et le fonctionnement de l'enseignement spécialisé. Un questionnaire en ligne à grande échelle, a été répondu par 1.202 professeurs de classes d'éducation spéciale. Ces données incluent des participants de 20 provinces et plus de 100 municipalités. Les résultats ont révélé des problèmes dans contraturno, classes d'éducation spéciale est insuffisant et nécessite le soutien de professionnels de la santé et des soins que l'étudiant est, dans la plupart des cas, le service est deux fois par semaine individuellement.

Mots-clés:Éducation spéciale. L’inclusion scolaire. Services D’éducation Spécialisée.

\section{INTRODUÇÃO}

O foco deste estudo é conhecer e analisar, em âmbito nacional, o funcionamento e a organização das Salas de Recursos Multifuncionais (SRM) dentro do Programa de Implantação, criado pela Secretaria de Educação Especial do Ministério da Educação (MEC) que apoia, desde 2005, a criação e a expansão do serviço de Atendimento Educacional Especializado (AEE). Para isso, foi aplicado um questionário on-line (survey) que coletou respostas de 1.202 professores da SRM de todas as regiões brasileiras, incluindo mais de 100 municípios em 20 estados. 
A partir da década de 1960, com a luta pelos Direitos Humanos, houve a criação da proposta de unificação da educação especial com a educação comum, bem como argumentos racionais e científicos que apontaram que a colocação das pessoas com deficiência na escola seria benéfica, tanto para as pessoas com deficiência quanto para seus pares sem deficiência. A princípio, tal proposta baseava-se em um conceito denominado integração, o qual pressupunha que os alunos deveriam se adaptar ao ambiente escolar. Mendes (2006) destaca críticas importantes a esse conceito, em que a passagem de alunos com necessidades educacionais especiais acontecia de um nível de serviço mais segregado para outro, supostamente mais integrador. No entanto, na prática, essas transições dificilmente aconteciam, pois dependiam unicamente dos progressos da criança (MENDES, 2006).

O conceito de integração foi substituído pelo de inclusão, o qual coloca que é o ambiente escolar que deve se adaptar ao aluno e não o contrário. Logo, a inclusão é um avanço em relação à integração, pois demanda a reestruturação do sistema comum de ensino (JANNUZZI, 2006).

A inclusão passou a ser debatida internacionalmente na década de 1990, por meio de acordos internacionais, destacando-se os debates da Conferência Mundial sobre Educação para Todos, em Jomtien, Tailândia, promovida pelo Banco Mundial, pela Organização das Nações Unidas para a Educação, a Ciência e a Cultura (UNESCO) e pelo Fundo das Nações Unidas para a Infância (UNICEF), que estimularam "o consenso sobre a necessidade de concentrar esforços para atender as necessidades educacionais de inúmeros alunos até então privados do direito de acesso, ingresso, permanência e sucesso na escola básica" (MENDES, 2006, p. 295).

Em continuidade, a Declaração de Salamanca, elaborada em 1994 na Conferência Mundial sobre Necessidades Educacionais Especiais: Acesso e Qualidade, responsável por difundir a filosofia da inclusão, de forma que esta passou a ser discutida em todo o mundo de maneira ampla. No contexto brasileiro, em relação à inclusão escolar, tem-se como marco a Constituição Federal de 1988 e a Lei no 9.394/96 - Lei das Diretrizes e Bases (LDB) - (BRASIL, 1996), as quais apontaram como sendo um direito o Atendimento Educacional Especializado, porém a primeira restringe esse atendimento às pessoas com deficiência, enquanto a segunda estende o atendimento aos "educandos com necessidades especiais" (BUENO; MELETTI, 2011). Ao mesmo tempo, os autores destacam que apesar da mudança de nomenclatura, uma análise cautelosa permite perceber 
que no texto da LDB o termo "necessidades especiais" é usado como sinônimo de "deficiência", exceto no Inciso II do Art. 59, onde é referida a possibilidade de aceleração escolar para pessoas com altas habilidades / superdotação (BRASIL, 1996).

Nessa mesma época, iniciou-se um processo de disseminar a proposta de educação inclusiva no Brasil, como consequência dos seguintes aspectos: 1) organização dos movimentos sociais das pessoas com deficiência e das associações de pais e profissionais de pessoas com deficiência; 2) mudança de proposições e ações sobre as pessoas com deficiência; 3) elaboração dos acordos internacionais direcionados às pessoas com deficiência, os quais foram aceitos e ratificados pelo Brasil (KASSAR, 2012).

Apenas após a publicação da Política Nacional de Educação Especial na Perspectiva da Educação Inclusiva (PNEE-EI), em 2008, que se tornou, cada vez mais frequente, a inserção da educação especial nas políticas educacionais. A PNEE-EI discorre sobre diferentes diretrizes que visam fundamentar uma política pública voltada à inclusão escolar, a partir da defesa pela inclusão dos alunos Público-alvo da Educação Especial (PAAE) exclusivamente na classe comum e, no contraturno, no Atendimento Educacional Especializado, excluindo, com isso, os serviços segregados.

\section{O FUNCIONAMENTO E A ORGANIZAÇÃO DO ATENDIMENTO EDUCACIONAL ESPECIALIZADO}

Diversas políticas foram elaboradas com a finalidade de regulamentar o serviço de AEE, o qual deve ser ofertado nas SRM, sendo dever dos sistemas de ensino garantir acesso à classe comum e ao serviço de AEE para os alunos PAEE (BRASIL, 2011). As SRM consistem em "[...] ambientes dotados de equipamentos, mobiliários e materiais didáticos e pedagógicos para a oferta do atendimento educacional especializado" (BRASIL, 2011, p. 1). Como garantia da efetivação dessa dupla matrícula, há a dupla contabilização do Fundo de Manutenção e Desenvolvimento da Educação Básica e de Valorização dos Profissionais da Educação (FUNDEB) para os alunos que cursam o ensino regular e o AEE no contraturno (BRASIL, 2011).

O AEE consiste em um

[...] conjunto de atividades, recursos de acessibilidade e pedagógicos organizados institucional e continuamente, prestado das seguintes formas:

I - complementar à formação dos estudantes com deficiência, transtornos globais do desenvolvimento, como apoio permanente e limitado no tempo e na frequência dos estudantes às salas de recursos multifuncionais; ou 
II - suplementar à formação de estudantes com altas habilidades ou Superdotação. (BRASIL, 2011, p. 1)

Ele deve ser parte integrante do projeto político-pedagógico da escola, havendo participação da família, tendo os seguintes objetivos:

I - prover condições de acesso, participação e aprendizagem no ensino regular e garantir serviços de apoio especializados de acordo com as necessidades individuais dos estudantes;

II - garantir a transversalidade das ações da educação especial no ensino regular; III - fomentar o desenvolvimento de recursos didáticos e pedagógicos que eliminem as barreiras no processo de ensino e aprendizagem; e

IV - assegurar condições para a continuidade de estudos nos demais níveis, etapas e modalidades de ensino. (BRASIL, 2011, p. 1)

O funcionamento pedagógico no Atendimento Educacional Especializado envolve as situações de ensino e aprendizagem e as metodologias usadas nas SRM. Isso abrange a organização do tempo e do espaço físico, para determinar os critérios a serem usados para a distribuição dos atendimentos em grupo ou individuais. Envolve também a elaboração das atividades, com a preparação dos materiais e dos recursos a serem utilizados (PASIAN; MENDES; CIA, 2014; CARDOSO; TARTUCI, 2013).

O professor de educação especial das SRM tem papel fundamental, organiza o funcionamento do AEE e faz o planejamento individual para o aluno PAEE, atendendo às particularidades de cada um. Muitas vezes, os alunos possuem a mesma deficiência, no entanto, por terem características diferentes, é preciso verificar a melhor forma de alcançar resultados positivos para a aprendizagem desse aluno de acordo com suas dificuldades e potencialidades.

Como relata Cardoso e Tartuci (2013, p. 3307) em um estudo realizado sobre o funcionamento do AEE:

O planejamento irá influenciar na organização do trabalho pedagógico como um todo nas SRM, visto que ele precede a ação nessas salas e ao mesmo tempo é essa ação de planejar que definirá a melhor forma de trabalho, não apenas em relação às metodologias e atividades de ensino a serem desenvolvidas com o aluno, mas também o melhor modo de organizar o funcionamento dessas salas de maneira a favorecer a aprendizagem dos alunos respondendo as suas necessidades educacionais.

Nota-se que atualmente há uma série de legislações que regulamentam as políticas de inclusão escolar de acesso à classe comum para os alunos PAEE. Porém, é necessário verificar se essa política e, consequentemente, esse serviço é, de fato, efetivo, garantindo, assim, não só o acesso, mas a permanência e o sucesso dos alunos do AEE. 
Com vista a essa perspectiva, o presente trabalho levantou dados sobre a opinião dos professores de SRM, no âmbito de seus municípios, relativos à organização e ao funcionamento do AEE. Como relatado no estudo de Pasian, Mendes e Cia (2013, p. 19):

\footnotetext{
A Educação Especial deve procurar as melhores formas de avaliar e promover educação de qualidade para crianças com deficiência, superdotação/altas habilidades e transtorno global do desenvolvimento. Também deve, enquanto área de conhecimento científico, aprofundar o conhecimento sobre o assunto produzindo mais pesquisas sobre a temática da inclusão escolar.
}

Evidencia-se a necessidade de pesquisas e artigos que investiguem e divulguem o trabalho nas Salas de Recursos Multifuncionais. Por meio disso, gerar material a ser analisado para propostas de adequação e melhora do ensino para os alunos com necessidades educacionais especiais.

\section{METODOLOGIA}

Por ter como objetivo central verificar como é a realidade vivenciada pelos professores das Salas de Recursos Multifuncionais sobre o funcionamento e a organização do Atendimento Educacional Especializado, em longa escala, em diferentes regiões brasileiras, optouse por utilizar como instrumento um questionário on-line (survey), o qual foi enviado a professores das SRM em âmbito nacional por meio do site do Observatório Nacional de Educação Especial (ONEESP). O survey foi elaborado tomando como base "falas reais" de professores de SRM advindos de um estudo preliminar que envolveu uma pesquisa colaborativa a partir de uma série de encontros reflexivos de um pesquisador com os professores de SRM (DAMASCENO; PEREIRA, 2014; MENDES; CIA, 2012; MILANESI; MENDES, 2015; REIS; ANJOS, 2014; SANTOS et al., 2015).

O questionário foi submetido a juízes para validação de conteúdo e foi aplicado um piloto com três professores de SRM para validação semântica. Depois de realizadas as adaptações sugeridas pelos juízes e pelos professores que participaram da aplicação do questionário piloto, o questionário foi inserido em um sítio para acesso dos professores de SRM de todo o Brasil.

O recrutamento foi feito pelos pesquisadores envolvidos na rede do ONEESP. A divulgação continha instruções sobre como ter acesso ao endereço eletrônico. Ao acessar o sítio do questionário, os participantes assinavam um termo de consentimento livre e esclarecido e, a partir disso, tinham acesso às questões. O questionário ficou disponível on-line durante oito meses, no período entre novembro de 2013 e junho de 2014. 
O survey contém 84 questões no total. Contém 12 questões sobre informações do professor que envolvem nome, data de nascimento, local de atuação, formação e experiência. Em seguida, dispõe 68 questões em escala likert para respostas: concordo totalmente, concordo parcialmente, nem concordo/ nem discordo, discordo parcialmente e discordo totalmente. Essas respostas envolvem os três eixos do projeto ONEESP: avaliação, formação e funcionamento das SRM. No fim, possui quatro questões abertas para o professor deixar um recado para seus alunos, pais de seus alunos, para escola e para os políticos. O questionário foi aplicado em larga escala e coletaram-se dados de 1.202 professores de SRM das redes municipais de ensino, com participantes de 20 estados em mais de 100 cidades, esse é um fator importante, pois traz dados relativos a diferentes regiões brasileiras.

\section{RESULTADOS E DISCUSSÃO}

Para fins deste estudo, foram selecionadas questões que diziam respeito ao funcionamento do serviço de AEE. Os dados foram confrontados com políticas públicas e com a literatura nacional, incluindo diversos estudos do ONEESP com professores de SRM e profissionais da gestão da educação especial.

A política atual de inclusão escolar utiliza o AEE como serviço para garantir o apoio necessário ao educando PAEE dentro do contexto do ensino regular. Para tal, o aluno PAEE deve frequentar as SRM no contraturno da classe comum (BRASIL, 2011). Porém, como se observa na Tabela 1, os participantes declararam que há local onde o AEE não ocorre no contraturno.

TABELA 1 - Ocorrência do funcionamento do AEE no contraturno da sala comum

\begin{tabular}{|c|c|c|c|c|c|}
\hline Respostas & $\begin{array}{c}\text { Concordo } \\
\text { totalmente }\end{array}$ & $\begin{array}{c}\text { Concordo } \\
\text { parcialmente }\end{array}$ & $\begin{array}{c}\text { Nem } \\
\text { concordo/ } \\
\text { nem discordo }\end{array}$ & $\begin{array}{c}\text { Discordo } \\
\text { parcialmente }\end{array}$ & $\begin{array}{c}\text { Discordo } \\
\text { totalmente }\end{array}$ \\
\hline$\%$ & $73,6 \%$ & $14,8 \%$ & $3,6 \%$ & $2,8 \%$ & $5,3 \%$ \\
\hline
\end{tabular}

Fonte: Elaboração pelos autores.

Há duas suposições quanto a esse fato, a primeira consiste na impossibilidade de o aluno ir até a escola novamente, no contraturno. Como exemplo, cita-se a cidade de Niterói, onde dados coletados com professores de SRM, por meio de grupo focal, apontaram que os alunos participam do AEE no mesmo turno da classe comum, por dificuldades relacionadas ao transporte desses alunos até a escola (COSTA; SANTOS, 2015). Resultado semelhante foi encontrado em 
outros estudos de cidades de diferentes estados brasileiros (ANACHE et al., 2014; SANTOS et al., 2015; ARAÚJO; MARTINS; SILVA, 2015).

Quanto à segunda suposição, esta consiste no fato de que existem escolas que adotam a jornada integral e, nesses casos, não haveria possibilidade de contraturno, uma vez que o aluno teria atividades em ambos os períodos, como relatado no estudo realizado por Santos et al. (2015) que corrobora essa situação, esse estudo foi realizado por meio de grupo focal com professores de SRM, em uma cidade do interior do estado de São Paulo.

É necessário ressaltar que, apesar de existirem dificuldades que impossibilitam o atendimento no contraturno, é problemático que este se dê no mesmo turno da classe comum, pois, nesse caso, o aluno sai no horário letivo para as SRM, o que ocasiona substituição do ensino regular pelo Atendimento Educacional Especializado. O mesmo ocorre em situações em que o aluno frequenta o ensino integral e, com isso, não tem possibilidade de frequentar o AEE no contraturno, passando a fazê-lo no lugar de alguma aula.

Milanesi e Mendes (2015) apontaram casos, em um município do interior do estado de São Paulo, em que o atendimento não ocorria no contraturno com a finalidade de garanti-lo, uma vez que a família não almejava levar o aluno até a escola para o contraturno, pois ele já frequentava outros serviços que demandavam esse período. Além desses casos supracitados, outro estudo mostra uma determinada situação em que a aluna vai para a SRM durante o horário de aula regular porque a aluna não gosta de ficar na sala de aula e, dessa forma, não fica andando pela escola (DUBOC; RIBEIRO, 2015). Essa situação é ainda mais grave, pois não se trata nem ao menos de uma problemática, de fato, como nos outros dois casos, e sim do uso do serviço para uma finalidade completamente fora da função do foi proposto.

Questionou-se também aos participantes se eles recebiam apoio para o atendimento nas SRM de serviços públicos de saúde e/ ou de assistência social. Isso pode observado na Tabela 2.

TABELA 2 - Relação dos participantes que apontaram receber apoio para 0 atendimento em SRM de serviços públicos de saúde e/ ou assistência social

\begin{tabular}{|c|c|c|c|c|c|}
\hline Respostas & $\begin{array}{c}\text { Concordo } \\
\text { totalmente }\end{array}$ & $\begin{array}{c}\text { Concordo } \\
\text { parcialmente }\end{array}$ & $\begin{array}{c}\text { Nem } \\
\text { concordo/ } \\
\text { nem discordo }\end{array}$ & $\begin{array}{c}\text { Discordo } \\
\text { parcialmente }\end{array}$ & $\begin{array}{c}\text { Discordo } \\
\text { totalmente }\end{array}$ \\
\hline $\begin{array}{c}\text { Serviços públicos } \\
\text { de saúde }\end{array}$ & $7 \%$ & $29,7 \%$ & $5,1 \%$ & $22,6 \%$ & $35,6 \%$ \\
\hline $\begin{array}{c}\text { Assistência } \\
\text { social }\end{array}$ & $9,2 \%$ & $25,5 \%$ & $8 \%$ & $18,4 \%$ & $38,9 \%$ \\
\hline
\end{tabular}

Fonte: Elaboração pelos autores. 
Os dados revelam que, nos dois casos, menos da metade dos professores afirmou receber apoio (total ou parcialmente) de serviços públicos para o atendimento nas SRM (36,7\% para serviços públicos de saúde e $34,7 \%$ para assistência social). Essa situação é problemática, pois ocorrem casos em que a demanda do aluno vai além da pedagógica, de tal forma que somente o professor não é capaz de atendê-la (ARAÚJO; MARTINS; SILVA, 2015). Como exemplo, os alunos com paralisia cerebral, que demandam, muitas vezes, de acompanhamento de outros profissionais, como fisioterapeuta e terapeuta ocupacional. Torna-se importante, portanto, a junção de serviços públicos de saúde para melhoraria do trabalho com determinados alunos para melhora do AEE.

Ivanilde Oliveira, Anna Oliveira e Lucélia Rabelo (2015) verificaram, segundo as respostas de professores das SRM da cidade de Marabá, que uma das causas de o professor não atender mais alunos por semana se dava devido à falta de suporte de profissionais da saúde. Santos et al. (2015), por sua vez, destacaram que os professores de SRM apontam uma demanda de profissionais da saúde e que existe apenas uma fonoaudióloga e uma psicóloga contratadas pelo serviço público de saúde. Os profissionais da saúde possuem conhecimento diferenciado em relação ao professor das SRM, de tal forma que poderia haver troca constante e colaborativa, o que contribuiria para a educação dos alunos PAEE. A necessidade desse trabalho colaborativo entre educação e saúde é corroborada por diversos estudos (ANACHE et al., 2014; ANJOS et al., 2015; ARAÚJO; MARTINS; SILVA; 2015; FARIAS et al., 2015; PASIAN, MENDES, CIA, 2013).

Com isso, aflora a necessidade de discutir outro assunto indispensável no que tange ao funcionamento do serviço de AEE, este consiste na quantidade das SRM dispostas nos municípios brasileiros. Questionou-se, como pode ser visto na Tabela 3, se a quantidade de SRM é suficiente para atender à demanda, e a maioria afirmou não ser suficiente $(60,2 \%)$.

TABELA 3 - Relação de participantes que declararam existir, em seu respectivo município, número insuficiente de SRM para atender à demanda

\begin{tabular}{|c|c|c|c|c|c|}
\hline Respostas & $\begin{array}{c}\text { Concordo } \\
\text { totalmente }\end{array}$ & $\begin{array}{c}\text { Concordo } \\
\text { parcialmente }\end{array}$ & $\begin{array}{c}\text { Nem } \\
\text { concordo/ } \\
\text { nem discordo }\end{array}$ & $\begin{array}{c}\text { Discordo } \\
\text { parcialmente }\end{array}$ & $\begin{array}{c}\text { Discordo } \\
\text { totalmentew }\end{array}$ \\
\hline$\%$ & $29,5 \%$ & $30,7 \%$ & $9,5 \%$ & $13,5 \%$ & $16,8 \%$ \\
\hline
\end{tabular}

Fonte: Elaboração pelos autores. 
Quanto a esse fato, a discussão necessária é ampla e tange, inclusive, à distribuição de verba para os municípios. Mas, para além da distribuição de verba, é preciso levar em conta a forma como é declarada a quantidade de alunos PAEE.

Segundo a legislação, deve ser efetivo o funcionamento das SRM, devendo haver oferta de AEE para os alunos PAEE que forem devidamente cadastrados no Censo Escolar/ Instituto Nacional de Estudos e Pesquisas Educacionais Anísio Teixeira (INEP), de tal forma que é por meio do censo que o MEC faz o planejamento do programa de expansão das SRM, bem como cria novas ações nas SRM já em funcionamento. Ações essas que consistem em: atualização de itens; conversão de itens da sala tipo II para a sala tipo I; apoio complementar por meio do Programa Escola Acessível e do Programa de Formação Continuada de Professores na Educação Especial; visita técnica e informativa por meio da distribuição da Revista Inclusão e demais publicações pedagógicas do MEC (BRASIL, 2010).

Sendo assim, há a necessidade de se levantar a possibilidade de que existem alunos que frequentam as SRM mesmo sem ser PAEE. Mas, com os dados coletados, só é possível realizar as duas suposições supracitadas, de tal forma que é necessário realizar outros estudos para se averiguar, de fato, o motivo pelo qual a quantidade de SRM não atende à demanda. O fato é que não se pode deixar de debater essa questão, uma vez que ela implica diretamente na qualidade do serviço e, consequentemente, na qualidade da educação dos alunos PAEE.

Outra questão realizada foi sobre o material utilizado nas SRM, cujo resultado está descrito na Tabela 4. Foi perguntado aos professores se eles possuíam, em suas respectivas SRM, todo material necessário para trabalhar, e apenas cerca da metade respondeu positivamente $(52,3 \%)$, sendo que $14,7 \%$ concordaram totalmente.

TABELA 4 - Relação da opinião de participantes que apontaram possuir, em suas respectivas SRM, todo material necessário para trabalhar

\begin{tabular}{|c|c|c|c|c|c|}
\hline Respostas & $\begin{array}{c}\text { Concordo } \\
\text { totalmente }\end{array}$ & $\begin{array}{c}\text { Concordo } \\
\text { parcialmente }\end{array}$ & $\begin{array}{c}\text { Nem } \\
\text { concordo/ } \\
\text { nem discordo }\end{array}$ & $\begin{array}{c}\text { Discordo } \\
\text { parcialmente }\end{array}$ & $\begin{array}{c}\text { Discordo } \\
\text { totalmente }\end{array}$ \\
\hline$\%$ & $14,7 \%$ & $37,6 \%$ & $5,2 \%$ & $23,1 \%$ & $19,4 \%$ \\
\hline
\end{tabular}

Fonte: Elaboração pelos autores. 
Duas possibilidades são iminentes quanto a esse resultado, a primeira consiste no fato de que nem todo material que deveria constar em uma SRM está disponível, a segunda é que o material disponibilizado é aquém do necessário para atender às reais necessidades do alunado que frequenta esse espaço. Ambas as hipóteses são preocupantes. Um exemplo dessa realidade pode ser averiguado no município de Nova Iguaçu (RJ), onde de forma recorrente há falta de material e os professores, por vezes, pagam com seu próprio dinheiro para ter o material necessário para trabalhar com os alunos nas SRM (DAMASCENO; PEREIRA, 2014). Outro estudo realizado por Victor, Cotonhoto e Souza (2015) com professores de SRM, por meio de relatos realizados advindos da participação de um grupo focal, levantou a ausência de estrutura física adequada e de material didático em algumas SRM, o que corrobora a primeira hipótese apresentada acima.

Há também casos em que se retrata a falta de adequação para a utilização do material, o que pode resultar no apontamento de que não existe o material adequado para trabalhar. Essa situação fica evidente no relato da fala de uma professora na cidade de Maceió (AL):

[...] Não temos quem faça essa manutenção e nem instalação, por exemplo: todo o material que tenho aqui está encaixotado e por que está encaixotado? Porque falta fiação na sala. Houve uma reforma, mas infelizmente a nossa sala não foi contemplada. (FUMES et al., 2015, p. 10)

Vários estudos, dentro da temática "material", têm como lócus para elaboração a adaptação de materiais, de tal forma que fica muito a cargo do professor a decisão pela elaboração do material, o que pode dificultar o desenvolvimento das atividades realizadas na SRM (ANACHE et al., 2014; ANJOS et al., 2015; ARAÚJO; MARTINS; SILVA, 2015; CARDOSO; TARTUCI; BORGES, 2015; MIRANDA et al., 2015; CAPELLINI et al., 2015; DUBOC; RIBEIRO, 2015; SANTOS et al., 2015; SILVA-PERDIGÃO; SILVA, 2014). A disponibilidade de materiais adequados pode facilitar e apoiar as atividades do professor no AEE, sendo que muitos professores precisam buscar/ adaptar/ criar materiais além dos disponíveis e, por isso, apontaram não possuir o material necessário.

Outros aspectos que interferem diretamente na qualidade do Atendimento Educacional Especializado estão dispostos na Tabela 5. 
TABELA 5 - Dados relacionados à participação dos alunos PAEE nas SRM

\begin{tabular}{|c|c|c|c|c|c|}
\hline Respostas & $\begin{array}{c}\text { Concordo } \\
\text { totalmente }\end{array}$ & $\begin{array}{c}\text { Concordo } \\
\text { parcialmente }\end{array}$ & $\begin{array}{c}\text { Nem } \\
\text { concordo/ } \\
\text { nem discordo }\end{array}$ & $\begin{array}{c}\text { Discordo } \\
\text { parcialmente }\end{array}$ & $\begin{array}{c}\text { Discordo } \\
\text { totalmente }\end{array}$ \\
\hline $\begin{array}{c}\text { Trabalho individual } \\
\text { com aluno nas SRM }\end{array}$ & $33 \%$ & $42,3 \%$ & $5,2 \%$ & $11,4 \%$ & $8,2 \%$ \\
\hline $\begin{array}{c}\text { 0 atendimento } \\
\text { ocorre entre uma } \\
\text { e duas vezes por } \\
\text { semana }\end{array}$ & $67 \%$ & $18,6 \%$ & $3,7 \%$ & $5 \%$ & $5,7 \%$ \\
\hline $\begin{array}{c}\text { Os atendimentos } \\
\text { duram em torno de } \\
\text { uma hora }\end{array}$ & $45,8 \%$ & $27 \%$ & $4,4 \%$ & $8,8 \%$ & $14 \%$ \\
\hline
\end{tabular}

Fonte: Elaboração pelos autores.

A Tabela 5 refere-se à frequência, à permanência e à duração da participação dos alunos Público-alvo da Educação Especial nas SRM. Também discorre sobre o número de alunos atendidos.

Relativo ao atendimento do aluno nas SRM, pode ser observado na Tabela 5 que a maioria dos participantes apontou que o atendimento ocorre individualmente $(75,3 \%)$. De acordo com alguns estudos com professores das SRM, por meio de seus relatos, a forma de atendimento é variável, trabalham tanto de forma individual quanto em grupo, de acordo com as necessidades do aluno (ANACHE et al., 2014; CAPELLINI et al., 2015; CARDOSO; TARTUCI; BORGES, 2015; COSTA; SANTOS, 2015; DAMASCENO; PEREIRA, 2014; DUBOC; RIBEIRO, 2015; MILANESI; MENDES, 2015; MIRANDA et al., 2015; RAIMUNDO; BENDINELLI; PRIETO, 2015; REIS; ANJOS, 2014; SILVA-PERDIGÃO; SILVA, 2014; VICTOR; COTONHOTO; SOUZA, 2015). Houve destaque quanto ao atendimento individualizado para alunos com autismo, devido às singularidades desse tipo de educando, os professores alegaram ser mais produtivo trabalhar individualmente com o aluno para atingir melhores perspectivas de aprendizagem (OLIVEIRA, A.; OLIVEIRA, I., RABELO, 2015; SANTOS et al., 2015; RAIMUNDO; BENDINELLI; PRIETO, 2015).

O segundo aspecto contido na Tabela 5 discorre sobre o número de vezes por semana que os atendimentos ocorrem. A maioria dos professores $(85,6 \%)$ declara que o atendimento ocorre entre uma 
e duas vezes por semana. O terceiro aspecto questionado é relativo à duração do atendimento, neste $72,8 \%$ dos professores apontaram que os atendimentos duram em torno de uma hora. Os resultados correspondem de forma similar a alguns estudos que investigaram com os professores de SRM sobre a frequência e duração do atendimento realizado (DAMASCENO; PEREIRA, 2014; MILANESI; MENDES, 2015; REIS; ANJOS, 2014; SANTOS et al., 2015).

Foi também abordado sobre quem decide sobre a frequência semanal e a duração dos atendimentos. Isso pode ser observado a seguir, na Tabela 6 .

TABELA 6 - Relação de participantes que apontaram que em suas respectivas SRM são eles que definem a frequência semanal e duração dos atendimentos

\begin{tabular}{|c|c|c|c|c|c|}
\hline Respostas & $\begin{array}{c}\text { Concordo } \\
\text { totalmente }\end{array}$ & $\begin{array}{c}\text { Concordo } \\
\text { parcialmente }\end{array}$ & $\begin{array}{c}\text { Nem concordo/ } \\
\text { nem discordo }\end{array}$ & $\begin{array}{c}\text { Discordo } \\
\text { parcialmente }\end{array}$ & $\begin{array}{c}\text { Discordo } \\
\text { totalmente }\end{array}$ \\
\hline$\%$ & $36 \%$ & $31,1 \%$ & $6,8 \%$ & $10,1 \%$ & $16,1 \%$ \\
\hline
\end{tabular}

Fonte: Elaboração pelos autores.

Observa-se que a maioria dos participantes (67,1\%) declarou que a decisão é do professor de SRM. Por um lado, esse dado é positivo, pois o professor conhece os alunos e pode determinar com mais exatidão quanto à necessidade destes, por outro lado, destina-se grande responsabilidade ao professor, havendo necessidade de uma formação sólida que torne possível tal julgamento. Com isso, levantase a problemática que a formação do professor de educação especial não é suficiente para abranger a variedade do alunado atendido e suas especificidades. Ressalta-se a necessidade de haver formação docente de qualidade e de cursos de formação continuada que levem em conta a diversidade que ocorre dentro do PAEE e das necessidades do professor (MENDES et al., 2010; MILANESI; MENDES, 2015; OLIVEIRA, 2010; PRIETO, PAGNEZ, GONZALES, 2014).

\section{CONSIDERACְ̃̃ES FINAIS}

O estudo demonstrou que há muito para se investir no que tange ao modelo de sala de recursos, havendo vários locais onde a demanda é maior do que o serviço oferecido. Além disso, nota-se, com base na duração e na frequência do atendimento, que este segue uma ideia clínica, o que pode ser negativo se tem como objetivo a inclusão escolar. 
Tornou-se possível perceber, com base na utilização de estudos de diferentes regiões, que se encontra realidade muito parecida em locais distintos. Sendo assim, um estudo possível com base neste consiste em esmiuçar os dados do survey, buscando distinguir os resultados a partir das regiões dos participantes da pesquisa.

Algumas questões são importantes para refletir sobre situações abordadas, como a frequência dos alunos no contraturno, sendo que muitos alunos são atendidos, por diferentes motivos, no horário regular de aula, dessa forma, qual é o critério para decidir que aula ele deixa de frequentar para ir ao AEE? Os professores optam por substituir as matérias "menos relevantes"? Se sim, que matérias são essas? Aliás, há matérias menos relevantes? E quanto à utilização do espaço da SRM como local para que um determinado aluno "fique quieto"?

É necessário que os decretos que dispõem sobre o AEE sejam repensados com a finalidade de contemplar essas exceções e também prever fiscalização para o atendimento, para que seja garantido o direito a educação regular ao educando PAEE. Isso é fundamental para que essa educação tenha qualidade, auxiliando o sucesso e a permanência do aluno PAEE. O estudo de Prieto, Pagnez e Gonzales (2014) expõe a necessidade de formação continuada para os diferentes participantes da comunidade escolar, além de enfatizar a necessidade de acompanhamento do processo político: "É preciso aprimorar mecanismos de monitoramento das políticas para que sejam identificadas as distorções e necessidade de aprimoramentos e sejam organizadas intervenções mais especificas onde forem constatados deslocamentos de atribuições" (PRIETO; PAGNEZ; GONZALES, 2014, p. 737).

Alguns estudos mostram que os pais já levam o aluno a outros serviços e, por isso, não têm interesse que ele frequente o AEE ou não conseguem disponibilidade de horário (MILANESI; MENDES, 2015; SANTOS et al., 2015). Para esse tipo de situação, qual seria a solução? Os alunos PAEE, muitas vezes, demandam serviços de saúde ou de assistência social, e esse fato não pode ser desconsiderado. Isso ressalta a necessidade de haver uma equipe interdisciplinar, que possa auxiliar no processo de indicação e encaminhamento do aluno para o AEE, que, além de identificar se o aluno deve frequentar o AEE, vai revelar as potencialidades e os limites desse aluno para que haja investimento nas demandas de um atendimento adequado para suas necessidades especificas, o que pode ser melhor desenvolvido por uma equipe de profissionais (PASIAN; MENDES; CIA, 2013).

Pode-se concluir que o estudo realizado é de relevância por levantar dados que revelam o funcionamento e a organização do 
AEE em toda abrangência nacional. Com isso, questionamentos e demandas podem ser efetivados, além de servir de embasamento para estudos futuros dentro do tocante do funcionamento das SRM. Também vem ao encontro com a demanda de professores e pesquisadores, que buscam elaborar pesquisas integradas no tocante das políticas e práticas relacionadas à inclusão escolar no Brasil (MENDES; CIA, 2012; PASIAN; MENDES; CIA, 2014).

\section{REFERÊNCIAS}

ANACHE, A. A.; AgOstini, M. F.; BRUNO, M. G. M. ; SILVA, A. M. Atendimento Educacional Especializado nas Salas de Recursos Multifuncionais do Estado de Mato Grosso do Sul. In: MENDES, E. G.; CIA, F.; D’ AFFONSECA, S. M. (Org.). Inclusão escolar e a avaliação do público-alvo da Educação Especial. São Carlos: Marquezine \& Manzini: ABPEE, 2015. v. 2, p. 279-300.

ANJOS, H. P. et al. Atendimento educacional em Salas de Recursos Multifuncionais de escolas da rede municipal de Belém - Pará. In: MENDES, E. G.; CIA, F; TANNÚS-VALADÃO, G. (Org.). Organização e funcionamento do Atendimento Educacional Especializado. São Carlos: Marquezine \& Manzini: ABPEE, 2015. v. 4, p. 93-114.

ARAÚJO, E. S. O.; MARTINS, L. A. R. M.; SILVA, K. S. P. Os desdobramentos do Atendimento Educacional Especializado no cotidiano escolar. In: MENDES, E. G.; CIA, F.; TANNÚSVALADÃO, G. (Org.). Organização e funcionamento do Atendimento Educacional Especializado. São Carlos: Marquezine \& Manzini: ABPEE, 2015. v. 4, p. 269-292.

BRASIL. Casal Civil. Subchefia para Assuntos Jurídicos. Decreto $\mathbf{n}^{\mathbf{0}} \mathbf{7 . 6 1 1}$, de 17 de novembro de 2011. Dispõe sobre a educação especial, o Atendimento Educacional Especializado e dá outras providências. Brasília, DF, 2011. Disponível em: <http://www.planalto.gov.br/ ccivil_03/_Ato2011-2014/2011/Decreto/D7611.htm>. Acesso em: 10 ago. 2014.

BRASIL. Ministério da Educação. Secretaria de Educação Especial. Manual de Orientação: Programa de Implantação de Salas de Recursos Multifuncionais. Brasília, DF, 2010. Disponível em: $<$ http://portal.mec.gov.br/index.php?option=com_docman\&task=doc_ download\&gid=9936\&Itemid $>$. Acesso em: 10 ago. 2014.

BRASIL. Lei de Diretrizes e Bases da Educação Nacional. Lei n ${ }^{\circ}$ 9.394, de 20 de dezembro de 1996. Estabelece as diretrizes e bases da educação nacional. Disponível em: <https:// www2.senado.leg.br/bdsf/bitstream/handle/id/70320/65.pdf>. Acesso em: 15 mar. 2016.

BUENO, J. G. S; MELETTI, S. M. F. Os indicadores educacionais como meio de avaliação das políticas de educação especial no Brasil - 2000/2009. In: BUENO, J. G. S. Educação especial no Brasil: questões conceituais e de atualidade. São Paulo: EDUC, 2011. p. 159-182. CARDOSO, C. R.; TARTUCI, D. O funcionamento do Atendimento Educacional Especializado nas Salas de Recursos Multifuncionais e a atuação docente. In: ENCONTRO DA ASSOCIAÇÃO BRASILEIRA DE PESQUISADORES EM EDUCAÇÃO ESPECIAL, 8., 2013, Londrina. Anais... Londrina: ABPEE, 2013. p. 3.307-3.320.

CARDOSO, C. R.; TARTUCI, D.; BORGES, W. F. Atuação docente, o funcionamento e o papel do Atendimento Educacional Especializado em Salas de Recursos Multifuncionais em Catalão. In: MENDES, Enicéia G.; CIA, Fabiana; TANNÚS-VALADÃO, G. (Org.). Inclusão escolar em foco: organização e funcionamento do Atendimento Educacional Especializado. São Carlos: Marquezine \& Manzini; Marília: ABPEE, 2015. v. 4, p. 39-66. 
CAPELLINI, V. L. M. F. et al. Procedimentos de encaminhamento e avaliação dos alunos para Salas de Recursos Multifuncionais do município de Bauru. In: MENDES, Enicéia Gonçalves; CIA, Fabiana; D’AFFONSECA, Sabrina Mazo (Org.). Inclusão escolar e avaliação do público-alvo da Educação Especial. São Carlos: Marquezine \& Manzini: ABPEE, 2015. v. 2, p. 423-439.

COSTA, V. A.; SANTOS, L. B. Atendimento Educacional Especializado nas Salas de Recursos Multifuncionais: o que revelam as escolas públicas de Niterói (RJ). In: MENDES, Enicéia Gonçalves; CIA, Fabiana; TANNÚS-VALADÃO, Gabriela. (Org.). Atendimento Educacional Especializado nas Salas de Recursos Multifuncionais: o que revelam as escolas públicas de Niterói (RJ). São Carlos: Marquezine \& Manzini: ABPEE, 2015. v. 4, p. 315-330.

DAMASCENO, A. R.; PEREIRA, A. S. Organização do trabalho pedagógico: experiências/ interfaces entre a sala de recursos multifuncionais (SRM's) e a sala comum/regular no município de Nova Iguaçu-RJ: a organização do serviço. In: ENCONTRO DO OBSERVATÓRIO NACIONAL DE EDUCAÇÃO ESPECIAL, 4., 2014, São Paulo. Anais... São Paulo, 2014. p. 1-14.

DUBOC, M. J. O.; RIBEIRO, S. L. As Salas de Recursos Multifuncionais: organização, concepções e práticas. In: MENDES, E. G.; CIA, F.; TANNÚS-VALADÃO, G. (Org.). Organização e funcionamento do Atendimento Educacional Especializado. São Carlos: Marquezine \& Manzini: ABPEE, 2015. v. 4, p. 163-173.

FARIAS, A. Q. et al. Atendimento Educacional Especializado: política, concepção e diretrizes para o funcionamento da sala de recurso multifuncional no município de Campina Grande - Paraíba. In: MENDES, E. G.; CIA, F.; TANNÚS-VALADÃO, G. (Org.). Organização e funcionamento do Atendimento Educacional Especializado. São Carlos: Marquezine \& Manzini: ABPEE, 2015. v. 4, p. 247-268.

FUMES, N. L. F. et al. O funcionamento das Salas de Recursos Multifuncionais na rede municipal de educação de Maceió-AL. In: MENDES, E. G.; CIA, F.; TANNÚS-VALADÃO, G. (Org.). Inclusão escolar em foco: organização e funcionamento do Atendimento Educacional Especializado. São Carlos: Marquezine \& Manzini: ABPEE, 2015. v. 3, p. 137-162.

JANNUZZI, G. S. M. A educação do deficiente no Brasil, dos primórdios ao início do século XXI. 2. ed. Campinas: Autores Associados. p. 244, 2006.

KASSAR, M. C. M. Política de educação especial no Brasil: escolha de caminhos. In: MENDES, E. G.; ALMEIDA, M. A. (Org.). A pesquisa sobre inclusão escolar em suas múltiplas dimensões: teoria, política e formação. Marília: ABPEE, 2012. p. 93-104.

MENDES, E. G.; CIA, F. ONEESP - Um Observatório Nacional para a Comunidade da Educação Especial. In: MENDES, E. G.; ALMEIDA, M. A. (Org.). A pesquisa sobre inclusão escolar em suas múltiplas dimensões: teoria, política e formação. Marília: ABPEE, 2012. p. 363-383.

MENDES, E. G. A radicalização do debate sobre inclusão escolar no Brasil. Rev. Bras. Educ., Rio de Janeiro, v. 11, n. 33, p. 387-405, set./dez. 2006.

MENDES et al. Professores de educação especial e a perspectiva da inclusão escolar: uma nova proposta de formação. In: MENDES, E. G.; ALMEIDA, M. A. (Org.). Das margens ao centro: perspectivas para as políticas e práticas educacionais no contexto da educação especial inclusiva. Araraquara: Junqueira \& Marin, 2010. p. 61-78.

MILANESI, J. B.; MENDES, E. G. Funcionamento e desdobramentos do Atendimento Educacional Especializado: a dinâmica de Rio Claro - SP. In: MENDES, E. G.; CIA, F.; TANNÚSVALADÃO, G. (Org.). Inclusão escolar em foco: organização e funcionamento do Atendimento Educacional Especializado. São Carlos: Marquezine \& Manzini, 2015. v. 4, p. 367-388. 
MIRANDA, T. G. et al. A organização do trabalho pedagógico nas Salas de Recursos Multifuncionais. In: MENDES, E. G.; CIA, F.; TANNÚS-VALADÃO, G. (Org.). Organização e funcionamento do Atendimento Educacional Especializado. São Carlos: Marquezine \& Manzini: ABPEE, 2015. v. 4, p. 195-214.

OLIVEIRA, A. A. S. Inclusão escolar e formação de professores: o embate entre o geral e o especifico. In: MENDES, E. G.; ALMEIDA, M. A. (Org.). Das margens ao centro: perspectivas para as políticas e práticas educacionais no contexto da educação especial inclusiva. Araraquara: Junqueira \& Marin, 2010. p. 61-78.

OLIVEIRA, A. P.; OLIVEIRA, I. A.; RABELO, L. C. C. A avaliação em Salas de Recursos Multifuncionais de escolas da rede municipal de Marabá - Pará. In: MENDES, E. G.; CIA, F.; D’AFFONSECA, S. M. (Org.). Inclusão escolar e a avaliação do público-alvo da educação especial. São Carlos: Marquezine \& Manzini: ABPEE, 2015. v. 2, p. 71-96.

PASIAN, M. S.; MENDES, E. G.; CIA, F. Salas de Recursos Multifuncionais: revisão de artigos científicos. Revista Eletrônica de Educação, v. 8, n. 3, p. 213-225, 2014. Disponível em: < http:/ / www.reveduc.ufscar.br/index.php/reveduc/article/view/949/366>. Acesso em: 12 mar. 2016.

PASIAN, M. S.; MENDES, E. G.; CIA, F. O funcionamento pedagógico nas Salas de Recursos Multifuncionais: revisão de trabalhos em eventos científicos. Cadernos da FUCAMP, v. 12, n. 17, p. 17-27, 2013.

PASIAN, M. S.; VELTRONE, A. A.; CAETANO, N. C. S. P. Avaliações educacionais e seus resultados: revelando ou omitindo a realidade brasileira sobre o fracasso escolar. Revista Eletrônica de Educação, v. 6, n. 2, p. 440-456, nov. 2012. Disponível em: < http://www. reveduc.ufscar.br/index.php/reveduc/article/view/362/211>. Acesso em: 12 maio 2016.

PRIETO; R. G.; PAGNEZ; K. S. M. M.; GONZALES, R. K. Educação especial e inclusão escolar: tramas de uma política em implantação. Educação \& Realidade, Porto Alegre, v. 39, n. 3, p. 725-743, jul./set. 2014.

RAIMUNDO, E. A.; BENDINELLI, R. C.; PRIETO, R. G. Estrutura e funcionamento do Atendimento Educacional Especializado na rede municipal de ensino de São Paulo. In: MENDES, E. G.; CIA, F.; TANNÚS-VALADÃO, G. (Org.). Inclusão escolar em foco: organização e funcionamento do Atendimento Educacional Especializado. 1. ed. São Carlos: Marquezine \& Manzini: Associação Brasileira de Pesquisadores em Educação Especial, 2015. v. 1, p. 441-462.

REIS, G. B.; ANJOS, I. R. S. Funcionamento da sala de recursos no município de Aracaju. In: ENCONTRO DO OBSERVATÓRIO NACIONAL DE EDUCAÇÃO ESPECIAL, 4., 2014, São Paulo. Anais... São Paulo, 2014. p. 58-72.

SANTOS, V. et al. Organização e funcionamento das Salas de Recursos Multifuncionais do município de São Carlos. In: MENDES, E. G.; CIA, F.; TANNÚS-VALADÃO, G. (Org.). Inclusão escolar em foco: organização e funcionamento do Atendimento Educacional Especializado. São Carlos: Marquezine \& Manzini; Marília: ABPEE, 2015. v. 4, p. 389-406.

SILVA-PERDIGÃO, M. G.; SILVA, R. S. F. Atendimento na sala de recursos multifuncionais (SRM): relação com a sala de ensino regular (SER), planejamento, agenda e frequência dos alunos. In: ENCONTRO DO OBSERVATÓRIO NACIONAL DE EDUCAÇÃO ESPECIAL, 4., 2014, São Paulo. Anais... São Paulo, 2014. p. 82-98.

VICTOR, S. L.; COTONHOTO, L. A.; SOUZA, M. A. C. Organização do ensino nas Salas de Recursos Multifuncionais e a sua articulação com as classes comuns no Espírito Santo. In: MENDES, E. G.; CIA, F.; TANNÚS-VALADÃO, G. (Org.). Inclusão escolar em foco: organização e funcionamento do Atendimento Educacional Especializado. São Carlos: Marquezine \& Manzini; Marília: ABPEE, 2015. v. 4, p. 297-318. 
Submetido: $23 / 10 / 2015$

Aprovado: 31/05/2016

Contato:

Mara Silvia Pasian

Alameda das Hortências, 769,

São Carlos |SP| Brasil

CEP 13.566-533 